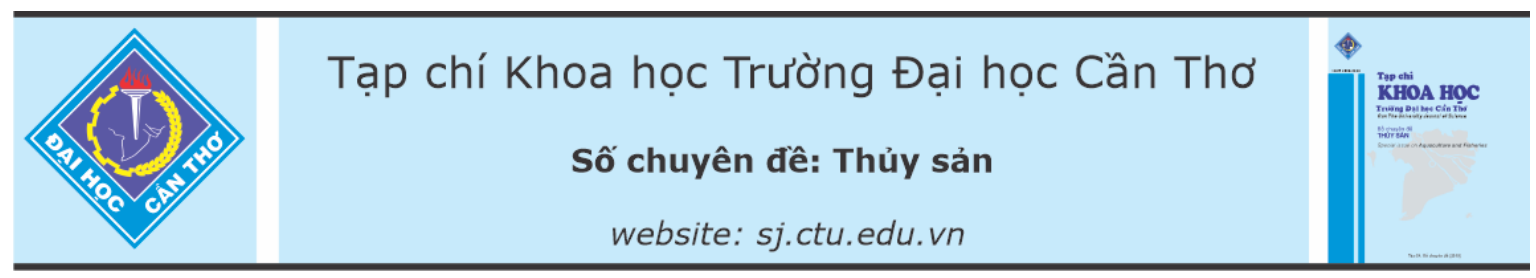

DOI:10.22144/ctu.jvn.2021.066

\title{
HIỆN TRẠNG KHAI THÁC THỦY SẢN VÙNG CỦAA SÔNG VEN BIỂN TỈNH SÓC TRĂNG
}

\author{
Võ Văn Nhịn ${ }^{1}$ và Trần Đắc Định ${ }^{2 *}$ \\ ${ }^{1}$ Sinh viên ngành Quản lý thủy sản khóa 41, Truờng Đại học Cần Tho' \\ ${ }^{2}$ Khoa Thủy sản, Truòng Đại học Cần Tho' \\ *Người chịu trách nhiệm về bài viết: Trần Đắc Định (email: tddinh@ctu.edu.vn)
}

\section{Thông tin chung:}

Ngày nhận bài: 22/02/2021

Ngày nhận bài sủa: 25/04/2021

Ngày duyệt đăng: 01/06/2021

Title:

Status of the coastal fisheries in Soc Trang province

\section{Tù khóa:}

Nguồn lợ thủy sản, quản lý thủy sản, tỉnh Sóc Trăng, vùng ven biển

\section{Keywords:}

Coastal areas, fisheries management, fisheries

resources, Soc Trang province

\begin{abstract}
The study was conducted from August to December 2018 through interviewing 106 fishermen in Tran De, Cu Lao Dung, and Long Phu districts in order to assess the current status of the fisheries in Soc Trang province. The results showed that there are 11 major kinds of fishing gears, in which trawl net (40\%) and push net (35\%) are the most common fishing gears in Soc Trang. The results also indicated that the mesh size $(2 a, \mathrm{~mm})$ of trawl net $2 a=19.3 \mathrm{~mm}$ is smaller than the fisheries regulations. Fishing seasons are all year round; however, the main fishing season is from the first - fourth month of lunar calendar. Push net and coastal bag-net fisheries earned the highest profit while the river bagnet fishery is the lowest profit. For the fisheries management, the registered fishing gears were only 53\%, trained fishermen (54\%), involved in fisheries management activities (73\%) and $92 \%$ of fishermen stated that fisheries resources are over-fishing (60\%).
\end{abstract}

\section{TÓM TẮT}

Nghiên cứu được thực hiện tù̀ tháng 8 đến tháng 12 năm 2018 thông qua phỏng vấn 106 hộ ngu dân tại các huyện Trần Đề, Cù Lao Dung và Long Phú nhằm đánh giá hiện trạng khai thác và quản lý nguồn lợi thủy sản ở tỉnh Sóc Trăng. Kết quả khảo sát đã xác định được 11 nghề khai thác thủy sản trong đó nghề luoói kéo và nghề te chiếm tỷ lệ cao nhất lần lượt là 40 và $35 \%$, đồng thời việc sử dụng kich thuớc mắt luoói nhỏ so với quy dịnh nhu nghề luới kéo $2 a=19,3 \mathrm{~mm}$. Măc dù có thể khai thác quanh năm, nhưng mùa vu khai thác chinh là tù tháng 1 đến tháng 4 âm lịch. Nghề te xiệp và đáy biển có lợi nhuận cao nhất trong khi thấp nhất thuộc về nghề đáy sông. Về công tác quản lý, kết quả cho thấy số họ có đăng kí ngu cu khai thác chi chiếm $53 \%$, được tham gia tập huấn là $54 \%$, được tuyên truyền bảo vệ nguồn lọi thủy sản (73\%) và 92\% ngu dân cho rằng nguồn lợi thủy sản đang suy giảm nhanh chóng, trong đó nguyên nhân chính là do khai thác quá múc (60\%).

\section{GIỚI THIỆU}

Sóc Trăng có chiều dài bờ biển khoảng $72 \mathrm{~km}$, trong đó có 3 cửa sông lớn là Trần Đề, Mỹ Thanh và
Định An với diện tích mặt nước khoảng 21.655 ha, nơi có nguồn lợi thủy sản dồi dào và đa dạng (Sở Nông nghiệp và Phát triển Nông thôn Sóc Trăng, 
2007). Theo Tổng cục thống kê (2018), sản lượng khai thác thủy sản của tỉnh Sóc Trăng năm 2015 là 62.700 tấn, đến năm 2016 tăng lên 65.813 tấn và năm 2017 tăng lên 66.730 tấn, điều đó cho thấy sản lượng khai thác luôn tăng hàng năm. Tuy nhiên, trữ lượng nguồn lợi thủy sản trong vùng lại đang suy giảm rất nghiêm trọng, hiện trạng khai thác quá mức và sử dụng ngư cụ cấm khá phổ biến, gây nên sự bất cập trong công tác quản lý. Ngoài ra, các thông tin về tình hình khai thác và quản lý nguồn lợi thủy sản vùng cửa sông ven biển cũng còn rất hạn chế; vì vậy việc đánh giá tình hình khai thác và quản lý nguồn lợi thủy sản ở khu vực này là rất cần thiết để làm cơ sở cho việc quản lý kịp thời nguồn lợi thủy sản theo hướng bền vững. Do đó, nghiên cứu "Đánh giá hiện trạng quản lý nguồn lợi thủy sản vùng cửa sông ven biển tỉnh Sóc Trăng" được thực hiện.

\section{PHƯƠNG PHÁP NGHIÊN CÚU}

\subsection{Thời gian và địa điểm}

Nghiên cứu được thực hiện từ tháng 8 đến tháng 12 năm 2018 ở vùng cửa sông 3 huyện Cù Lao Dung, Long Phú và Trần Đề tỉnh Sóc Trăng.

\subsection{Phương pháp thu thập và phân tích số liệu}

Số liệu được thu thập bằng phương pháp phỏng vấn ngẫu nhiên phân tầng có sự tham vấn của cán bộ quản lý thủy sản địa phương, với số mẫu phỏng vấn là 106 hộ ngư dân (chiếm khoảng 80 - $90 \%$ số hộ khai thác thủy sản vùng cửa sông) thuộc 3 huyện là Cù Lao Dung, Long Phú và Trần Đề. Nội dung phỏng vấn bao gồm: thông số tàu thuyền, kinh nghiệm khai thác, ngư cụ khai thác, sản lượng khai thác (không bao gồm ruốc), thuận lợi/khó khăn và đề xuất, biến động sản lượng khai thác, nguyên nhân của sự biến động, mức độ quan tâm về các hình thức phát triển nguồn lợi thủy sản, ... Ngoài ra, số liệu thứ cấp cũng được thu thập trong quá trình đi điều tra phỏng vấn, từ các tài liệu/báo cáo của cơ quan quản lý thủy sản địa phương; cũng như từ sách, tạp chí, báo cáo khoa học, ...

Phân tích ma trận SWOT được sử dụng để phân tích các điểm mạnh, điểm yếu, cơ hội và thách thức, từ đó đề ra các giải pháp cho việc bảo vệ nguồn lợi thủy sản trong vùng nghiên cứu. Các chỉ tiêu về hiệu quả tài chính của nghề khai thác cũng được xác định (cho 1 chuyến biển), bao gồm: Tổng thu nhập = Tổng số tiền bán thủy sản, Tổng chi phí $=$ Tổng chi phí biển đổi (chuyến biển) + Tổng chi phí cố định (chi phí khấu hao một chuyến), Lợi nhuận = Tổng thu nhập - Tổng chi phí.

\section{KẾT QUẢ VÀ THẢO LUẬN}

\subsection{Hiện trạng khai thác thủy sản}

Kết quả điều tra khảo sát cho thấy ngư dân khai thác thủy sản ở vùng cửa sông của tỉnh Sóc Trăng sử dụng tàu với công suất và trọng tải trung bình tương đối nhỏ (30,8 CV; 5,7 tấn). Tuy nhiên, do là các loại nghề truyền thống do đó ngư dân ở đây lại có kinh nghiệm khai thác lâu năm (trên 15 năm). Theo Nguyễn Thanh Long (2019), ở vùng cửa sông Cửu Long nói chung, công suất và trọng tải tàu tương đối cao hơn so với ở Sóc Trăng, tuần tự là 34,3-44,3 CV và 5,2-7,7 tấn.

Về ngư cụ khai thác, do vùng cửa sông ven biển rất đa dạng nguồn lợi thủy sản; do đó kết quả điều tra cho thấy có đến 11 loại nghề khai thác, trong đó nghề lưới kéo $(40 \%)$ và nghề te $(35 \%)$ là chiếm ưu thế; kế đến là các nghề như lưới rê $(16 \%)$, đáy biển (11\%), rập xếp (10\%), đáy sông ( $8 \%)$, các nghề khác như câu, lợp, đăng mé và lú $(5 \%)$. Trong khi đó nghề cá ở cả khu vực Đồng bằng sông Cửu Long có số lượng tàu khai thác lưới rê cao nhất $(50,8 \%)$, kế đến là nghề câu $(16,8 \%)$, lưới kéo $(16,5 \%), \ldots$ (Nguyễn Thanh Long và ctv., 2018).

Về kích thước măt lưới, kết quả cho thấy hầu hết các loại nghề khai thác ở đây đều sử dụng kích thước mắt lưới trung bình $(2 \mathrm{a})$ phù hợp với qui định của cơ quan quản lý Nhà nước theo Thông Tư số 02/2006/TT-BTS (Bộ Thủy sản, 2006). Tuy nhiên, kích thước mắt lưới phần đụt của lưới kéo là 19,3 $\mathrm{mm}$, trong khi đó theo quy định là $28 \mathrm{~mm}$ (Bảng 1). Việc sử dụng kích thước mắt lưới nhỏ hơn so với quy định là một trong những nguyên nhân khiến cho nguồn lợi thủy sản giảm nhanh chóng (Trịnh Kiều Nhiên \& Trần Đắc Định, 2012).

Bảng 1. Kích thước mắt lưới của các loại nghề khai thác

\begin{tabular}{lrr}
\hline $\begin{array}{l}\text { Nghề khai } \\
\text { thác }\end{array}$ & $\begin{array}{r}\text { Kích thước } \\
\text { mắt lưới lớn } \\
\text { nhất }(\mathbf{2 a}, \mathbf{m m})\end{array}$ & $\begin{array}{r}\text { Kích thước } \\
\text { mắt lưới nhỏ } \\
\text { nhất }(\mathbf{2 a}, \mathbf{m m})\end{array}$ \\
\hline Đáy song & $41,7 \pm 17,6$ & $18,3 \pm 2,9$ \\
Te (xiệp) & $39,9 \pm 14,8$ & $18,5 \pm 5,4$ \\
Đáy biền & $56,2 \pm 24,6$ & $21,2 \pm 8,5$ \\
Lưới kéo & $34,0 \pm 11,5$ & $19,3 \pm 5,5$ \\
Rập xếp & - & $20,7 \pm 3,5$ \\
Lưới rế & - & $32,4 \pm 18,1$ \\
\hline
\end{tabular}


Kết quả điều tra cũng cho thấy các nghề ở đây có thể khai thác quanh năm, tuy nhiên mùa vụ khai thác (có sản lượng cao) tập trung từ tháng 1 đến tháng 4 (âl) (Hình 1). Đặc biệt từ tháng 10 đến tháng 12 là giai đoạn thời tiết không thuận lợi (mưa bão), mặc dù khai thác với sản lượng cao, nhưng do tàu thuyền nhỏ, nên số chuyến khai thác lại thấp. Hình
1 cho thấy từ tháng 5 đến tháng 8 là giai đoạn có sản lượng khai thác thấp nhất. Đây còn là mùa vụ sinh sản của nhiều loài thủy sản, do đó chúng di cư vào vùng gần bờ, ven đảo, rừng ngập mặn nơi có nhiệt độ và địa hình thích hợp cho việc sinh sản; phần lớn vào mùa này cá phân tán vào các bãi đẻ nên làm cho sản lượng khai thác giảm.

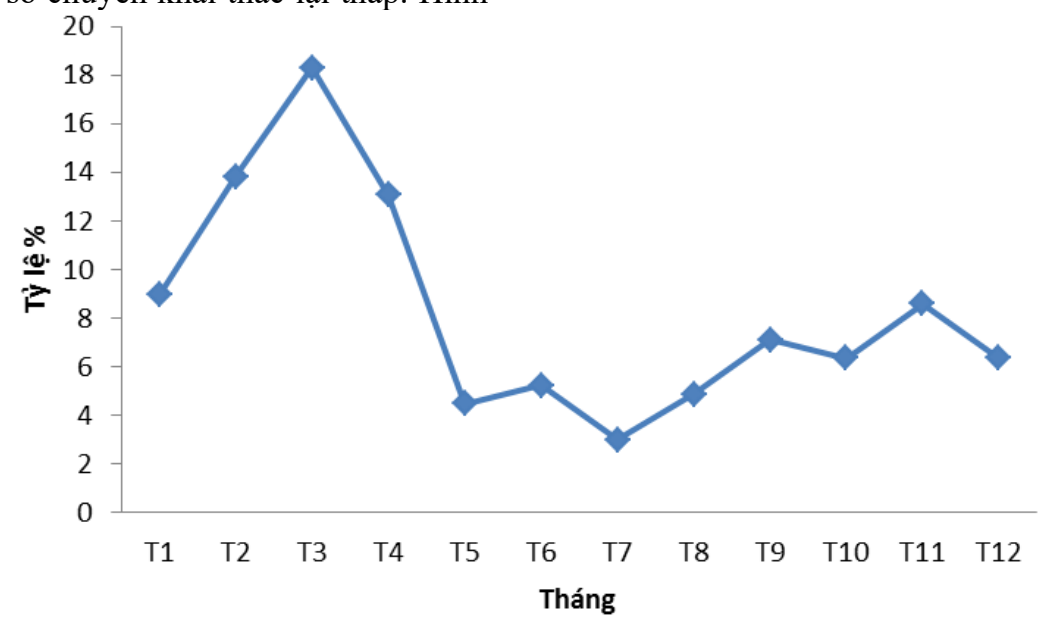

\section{Hình 1. Mùa vụ khai thác}

Về sản lượng và hiệu quả khai thác, kết quả điều tra cho thấy sản lượng khai thác cao nhất là nghề đáy biển $(150,2 \mathrm{~kg}$ /chuyến/miệng đáy) và nghề có sản lượng thấp nhất là nghề rập xếp $(53,3 \mathrm{~kg}$ /chuyến) (Bảng 2). Trong đó, nghề te xiệp và đáy sông ở đây chủ yếu là khai thác cá giống (cá bông lau, cá kèo,...) với sản lượng trung bình 1,6 -1,8 kg/chuyến. Kết quả cũng cho thấy lưới rê là nghề có sản lượng và doanh thu tương đối cao. Tuy nhiên, te xiệp và đáy biển lại là 2 nghề có lợi nhuận cao nhất, do chi phí của 2 nghề này tương đối thấp; lợi nhuận thấp nhất là nghề đáy sông (Bảng 3 ).

Bảng 2. Sản lượng và giá bán sản phẩm khai thác

\begin{tabular}{lrrrrrr}
\hline Nghề khai thác & Lưới rê & Lưới kéo & $\begin{array}{r}\text { Te xiệp } \\
\text { (Cá giống) }\end{array}$ & Đáy biển & $\begin{array}{r}\text { Đáy sông } \\
\text { (Cá giống) }\end{array}$ & Rập xếp \\
\hline Sản lượng (Kg/chuyến) & $107,4 \pm 108,1$ & $84,5 \pm 101,2$ & $1,8 \pm 1,01$ & $150,2 \pm 162,3$ & $1,6 \pm 0,7$ & $53,3 \pm 50,4$ \\
Năng suất (Tấn/CV/năm) & $0,65 \pm 0,26$ & $0,47 \pm 0,29$ & $0,006 \pm 0,002$ & $0,32 \pm 0,23$ & $0,005 \pm 0,001$ & $0,38 \pm 0,22$ \\
Giá bán (Ngàn đồng/kg) & $38,1 \pm 22,0$ & $47,74 \pm 31,7$ & $1.350,0 \pm 400,4$ & $30,12 \pm 11,68$ & $1.275,0 \pm 129,9$ & $44,2 \pm 34,5$ \\
\hline
\end{tabular}

Bảng 3. Hiệu quả tài chính của các nghề khai thác chính

\begin{tabular}{lrrr}
\hline Nghề khai thác & $\begin{array}{r}\text { Doanh thu } \\
\text { (triệu đồng/chuyến) }\end{array}$ & $\begin{array}{r}\text { Chi phí } \\
\text { (triệu đồng/chuyến) }\end{array}$ & $\begin{array}{r}\text { Lọi nhuận } \\
\text { (triệu đồng/chuyến) }\end{array}$ \\
Lưới rê & $4,75 \pm 5,05$ & $1,89 \pm 3,41$ & $2,87 \pm 3,86$ \\
Lưới kéo & $3,36 \pm 4,31$ & $1,68 \pm 1,63$ & $1,68 \pm 4,13$ \\
Te xiệp & $4,5 \pm 5,0$ & $1,66 \pm 1,05$ & $3,31 \pm 4,01$ \\
Đáy sông & $2,06 \pm 1,08$ & $1,21 \pm 0,43$ & $0,86 \pm 1,5$ \\
Đáy biến & $4,36 \pm 5,0$ & $1,23 \pm 0,34$ & $3,12 \pm 4,72$ \\
Rập xếp & $1,94 \pm 2,2$ & $0,32 \pm 0,46$ & $1,62 \pm 2,33$ \\
\hline
\end{tabular}

\subsection{Thuận lợi và khó khăn trong khai thác}

Về thuận lợi, kết quả phân tích cho thấy kinh nghiệm là yếu tố thuận lợi then chốt trong khai thác thủy sản, yếu tố quyết định để cho sản lượng cao. Thuận lợi kế tiếp là tận dụng được lao động gia đình giúp giảm chi phí trong khai thác (Bảng 4). Ngoài ra, mặc dù một vài loại nghề có lợi nhuận thấp, tuy nhiên ngư dân vẫn có được thu nhập ổn định; được sự quan tâm của Nhà nước trong việc phát triển cơ sở hạ tầng vùng ven biển, cũng như được hỗ trợ chuyển đồi nghề. 
Bảng 4. Thuận lọ̣i trong khai thác

\begin{tabular}{lcc}
\hline Nội dung & Số mẫu & Tỷ lệ \% \\
\hline Kinh nghiệm khai thác & 74 & 70 \\
Sử dụng được lao động gia đình & 42 & 40 \\
Thu nhập ồn định & 39 & 37 \\
Được Nhà nườc quan tâm & 22 & 21 \\
Ngư trường gần & 22 & 21 \\
Chi phí cố định thấp & 15 & 14 \\
\hline
\end{tabular}

Về khó khăn, kết quả điều tra cũng chỉ ra những khó khăn của nghề khai thác thủy sản như: hầu hết ngư dân $(65 \%)$ đều cho rằng khó khăn lớn nhất hiện nay là sự suy giảm nguồn lợi thủy sản (Bảng 5). Yếu tố khó khăn thứ hai đó là thời tiết hiện nay không ổn định $(63 \%)$ do biến đổi khí hậu, xuất hiện nhiều sóng gió và bão hơn. Khó khăn tiếp theo đó là nghề khai thác mang tính mùa vụ, do đó ngoài mùa khai thác chính thì sản lượng khai thác rất thấp, thậm chí không thể khai thác, do đó trong khoảng thời gian đó xem như không có việc làm. Việc thuê mướn lao động nghề cá cũng ngày càng khó khăn $(46 \%)$, do đây là nghề lao động nặng nhọc nhưng thu nhập không ổn định, trong khi đó các nghề lao động nhẹ nhàng và ổn định ngày càng hấp dẫn lao động địa phương hơn. Ngoài ra, ngư dân cũng gặp các khó khăn khác như giá bán và thu nhập không ổn định, chưa được Nhà nước hỗ trợ vốn đầu tư khai thác.

\section{Bảng 5. Khó khăn trong khai thác}

\begin{tabular}{lcc}
\hline Nội dung & Số mẫu & Tỷ lệ \% \\
\hline Nguồn lợi thủy sản ngày càng giảm & 69 & 65 \\
Thời tiết không ồn định & 67 & 63 \\
Khai thác chỉ theo mùa & 59 & 56 \\
Khó thuê mướn lao động & 49 & 46 \\
Thu nhập không ồn định & 31 & 29 \\
Nhiều chướng ngại vật làm hư hại ngư cụ & 28 & 26 \\
Giá bán không ồn định & 26 & 25 \\
Nghề thủ công nên lao động nặng nhọc & 24 & 23 \\
Chưa được hỗ trợ vốn trong khai thác & 21 & 20 \\
\hline
\end{tabular}

\subsection{Hiện trạng quản lý nguồn lợi thủy sản}

Kết quả điều tra về hiện trạng quản lý cho thấy số hộ khai thác có đăng ký với cơ quan quản lý nghề cá địa phương chỉ chiếm 53\% (Bảng 6), nguyên nhân là theo qui định quản lý nghề cá hiện nay, các nghề khai thác như te xiệp, rập xếp và đáy sông không còn được phép tiếp tục cho đăng ký khai thác. Kết quả cũng cho thấy $54 \%$ ngư dân được tập huấn về khai thác thủy sản, đặc biệt có đến $73 \%$ được tuyên truyền, giáo dục nâng cao nhận thức về việc bảo vệ nguồn lợi thủy sản.

\section{Bảng 6. Hiện trạng công tác quản lý nguồn lọ̣i thủy sản}

\begin{tabular}{lcc}
\hline Nội dung & Số mẫu(n=106) & Tỷ lệ \% \\
\hline Đăng ký ngư cụ khai thác & 56 & 53 \\
Được tập huấn về khai thác thủy sản & 59 & 54 \\
Được tuyên truyền về bảo vệ nguồn lợi thủy sản & 77 & 73 \\
\hline
\end{tabular}

Kết quả phân tích cũng cho thấy hầu hết ngư dân (87\%) đều nhận thức được rằng nguồn lợi thủy sản đã suy giảm rất nhiều so với cách đây 5 năm và $60 \%$ ngư dân cho rằng nguyên nhân chính của sự suy giảm đó là do khai thác quá mức, kế đến là do ô nhiễm môi trường nước vùng cửa sông ven biển $(16 \%)$. Kết quả phân tích năng suất khai thác (tấn/CV/năm) ở Bảng 2 cho thấy năng suất khai thác của các loại nghề khai thác thương phẩm biến động khá lớn, cao nhất là đối với nghề lưới rê $(0,65$ tấn/CV/năm) và thấp nhất là nghề đáy biển $(0,32$ tấn/CV/năm). Điều đó cũng cho thấy sự suy giảm nguồn lợi thủy sản chủ yếu ở các loại nghề cấm khai thác ven bờ như đáy biển $(0,32$ tấn/CV/năm) và rập xếp $(0,38$ tấn/CV/năm). Trịnh Kiều Nhiên và Trần Đắc Định (2012) cũng chỉ ra rằng nguồn lợi hải sản ở vùng ven biển Sóc Trăng của các loại nghề khai thác nói chung đã suy giảm khoảng $21 \%$, từ 0,47 tấn/CV vào năm 2005 xuống còn 0,37 tấn/ $\mathrm{CV}$ năm 2011.

\subsection{Phân tích SWOT}

Phân tích điểm mạnh (S), điểm yếu (W), cơ hội (O) và thánh thức $(\mathrm{T})$ của các nghề khai thác thủy 
sản; từ đó đề ra những giải pháp bảo vệ và phát triển nguồn lợi thủy sản, hệ sinh thái vùng cửa sông, cũng như tăng cường công tác quản lý nghề cá. Kết quả phân tích cho thấy các nghề khai thác thủy sản ven biển tỉnh Sóc Trăng có nhiều điểm mạnh và cơ hội. Tuy nhiên với hiện trạng suy giảm nguồn lợi thủy sản cùng với hệ sinh thái vùng của sông ven biển hiện nay thì điểm yếu và thách thức là không ít (Bảng 7). Do đó cần có sự quan tâm từ các cấp chính quyền địa phương đến nghề khai thác thủy sản vùng ven bờ, giải quyết bất cập trong thiếu hụt lao động nghề cá, đầu tư chuyển đổi các loại hình khai thác phù hợp với các quy định của Nhà nước. Ngoài ra cần có các giải pháp đồng bộ, khoa học và liên tục để có thể vừa bảo vệ đồng thời nguồn lợi thủy sản và hệ sinh thái vùng cửa sông ven biển của tỉnh Sóc Trăng nói riêng và của Đồng bằng sông Cửu Long nói chung.

\section{Bảng 7. Phân tích SWOT của các nghề khai thác thủy sản}

\section{Điểm mạnh (Strengths)}

$\mathrm{S}_{1}$ : Kinh nghiệm khai thác lâu năm;

$\mathrm{S}_{2}$ : Nghề có ngư trường truyền thống;

$\mathrm{S}_{3}$ : Đã có hệ thống quy định và quản lý;

$\mathrm{S}_{4}$ : Ngư dân tham gia có kinh nghiệm tham gia đồng quản lý

$\mathrm{S}_{5}$ : Ngư dân quan tâm đến các hình thức để phát triển nguồn lợi thủy sản;

$\mathrm{S}_{6}$ : Ngư dân được tổ chức khai thác theo tổ đội.

\section{Cơ hội (Opportunities)}

$\mathrm{O}_{1}$ : Đã có chính sách hỗ trợ khai thác xa bờ;

$\mathrm{O}_{2}$ : Nhiều cơ hội hợp tác trong và ngoài nước trong việc bảo vệ nguồn lợi thủy sản;

$\mathrm{O}_{3}$ : Điều kiện tự nhiên ưu đãi, thuận lợi.

\section{Điểm mạnh (S) và Cơ hội $(\mathrm{O})$}

- Kêu gọi phát triển đầu tư và hợp tác trong lĩnh vực nguồn lợi thủy sản;

- Triển khai thực hiện tốt hệ thống các quy định trong quản lý nghề cá;

- Thực hiện xây dựng các giải pháp/mô hình bảo vệ nguồn lợi; nguồn lợi; $\quad$ khai thác;

\section{Điểm yếu (Weaknesses)}

$\mathrm{W}_{1}$ : Thiếu vốn đầu tư khai thác;

$\mathrm{W}_{2}$ : Nghề lưới kéo và nghề đáy ảnh hưởng nhiều

đến nguồn lợi;

$\mathrm{W}_{3}$ : Tập quán khai thác gần bờ;

$\mathrm{W}_{4}$ : Đời sống kinh tế của ngư dân còn khó khăn;

$\mathrm{W}_{5}$ : Ngư cụ khai thác thô sơ, nặng nhọc;

$\mathrm{W}_{6}$ : Khai thác cá giống đang phổ biến;

$\mathrm{W}_{7}$ : Ý thức bảo vệ nguồn lợi thủy sản chưa cao;

$\mathrm{W}_{8}$ : Hoạt động khai thác thủy sản quanh năm.

\section{Thách thức (Threats)}

$\mathrm{T}_{1}$ : Nguồn lợi thủy sản đã và đang suy giảm nhanh chóng, ngư trường lại bị khai thác trái phép;

$\mathrm{T}_{2}$ : Ô nhiễm môi trường;

$\mathrm{T}_{3}$ : Lực lượng thanh tra, kiểm tra còn mỏng;

$\mathrm{T}_{4}$ : Chưa kiểm soát được triệt để ngư cụ khai thác;

$\mathrm{T}_{5}$ : Công tác quản lý còn bất cập.

\section{Điểm mạnh (S) và Thách thức (T)}

- Tăng cường lực lượng thanh tra, kiểm tra;

- Giới hạn ngư cụ khai thác bằng cách giới hạn giấy

phép khai thác;

- Cơ cấu lại đội tàu khai thác thủy sản;

- Giảm cường lực khai thác, quản lý tốt ngư trường

- Tăng cường hình thức khai thác theo tổ đội.

\section{Điểm yếu $(\mathrm{W})$ và Thách thức $(\mathrm{T})$}

- Quản lý hoạt động khai thác cá giống;

\section{Điểm yếu $(W)$ và Cơ hội $(O)$}

- Tập huấn kĩ thuật cho phát triển khai thác xa bờ;

- Đầu tư chuyển đổi nghề;

- Cải tiến ngư cụ và kỹ thuật khai thác;

- Kết hợp và phát triển nuôi trồng thủy sản để giảm áp lực khai thác.

- Quy định cụ thể mùa vụ khai thác;

-Tăng cường công tác tuyên truyền nâng cao ý thức cộng đồng;

- Chuyển đổi một số loại nghề khai thác sang khai thác xa bờ;

- Kết hợp với cơ quan quản lý môi trường xử lý nghiêm việc xả thải ra môi trường;

- Tăng cường xử lý các hành vi vi phạm qui định nghề cá.

\section{KẾT LUẬN}

Có 11 loại nghề khai thác thủy sản ở vùng cửa sông ven biển tỉnh Sóc Trăng, trong đó những nghề phổ biến là lưới kéo, te xiệp, lưới rê, đáy biển, rập xếp và đáy sông. Đây là các nghề khai thác truyền thống, có công suất khai thác thấp. Mặc dù có thể khai thác quanh năm, nhưng mùa vụ khai thác chính là từ tháng 1 đến tháng 4 âl. Về hiệu quả kinh tế, te xiệp và đáy biển là 2 nghề có lợi nhuận cao nhất, trong khi đáy sông có lợi nhuận thấp nhất. Lưới kéo cũng là một trong những loại nghề có lợi nhuận tương đối thấp; do đó, việc chuyển đổi nghề lưới kéo 
sẽ thuận lợi, vừa giải quyết được hiệu quả kinh tế vừa giảm được áp lực khai thác.

Trên cơ sở đánh giá hiện trạng quản lý nghề cá và phân tích SWOT, cần có các giải pháp đồng bộ, khoa học và liên tục để vừa bảo vệ được nguồn lợi thủy sản và hệ sinh thái vùng cửa sông ven biển của tỉnh Sóc Trăng nói riêng và của Đồng bằng sông Cửu Long nói chung.

\section{LỜI CẢM TẠ}

Nghiên cứu được sự hỗ trợ của Dự án Nâng cấp Trường Đại học Cần Thơ (VN14-P6) bằng nguồn vốn vay ODA từ Chính phủ Nhật Bản.

\section{TÀI LIẸU THAM KHẢO}

Nguyễn Thanh Long, Huỳnh Văn Hiền, Mai Viết Văn, Trần Đắc Định \& Naoki Tojo. (2018). Đánh giá hoạt động khai thác thủy sản ở Đồng Bằng sông Cửu Long. Tạp chi Khoa học Truờng Đại học Cần Tho, 54, 102-109.

Nguyễn Thanh Long. (2019). Đánh giá các thông số ngư cụ và kỹ thuật khai thác của một số nghề khai thác thủ công ở vùng cửa sông Cửu Long. Tạp chi Khoa học Công nghệ Nông nghiệp Việt Nam, 12, 189-192.

Sở Nông nghiệp và Phát triển Nông thôn tỉnh Sóc Trăng. (2007). Dự án rà soát, điều chỉnh và bổ sung quy hoạch tổng thể phát triển thủy sản tỉnh Sóc Trăng đến năm 2010 định hướng đến năm 2020.

Bộ Thủy sản. (2006). Hướng dẫn thực hiện nghị định của chính phủ số 59/2005/NĐ-CP ngày 04 tháng 5 năm 2005 về điều kiện sản xuất, kinh doanh một số ngành nghề thủy sản (số 02/2006/TTBTS). https://thuvienphapluat.vn/vanban/Doanh-nghiep/Thong-tu-02-2006-TT-BTShuong-dan-thuc-hien-Nghi-dinh-59-2005-NDCP-dieu-kien-san-xuat-kinh-doanh-nganh-nghethuy-san-10965.aspx\#tab3

Trịnh Kiều Nhiên \& Trần Đắc Định. (2012). Hiện trạng khai thác và quản lý nguồn lợi hải sản ở tỉnh Sóc Trăng. Tạp chi Khoa học Truờng Đại học Cần Tho, 24b, 46-55.

Tổng cục Thống kê. (2018). Số liệu thống kê sản lượng khai thác thủy sản tỉnh Sóc Trăng http:/www.gso.gov.vn. 